\title{
OPINIÃO
}

\section{Política Monetária, Arbitragem de Juro e Câmbio}

João Basilio Pereima Neto*

A combinação de política monetária com elevada taxa de juros em nível e política cambial está conduzindo o país à uma deterioração do saldo das transações correntes e ao aumento da vulnerabilidade por conta da entrada massiva de capital especulativo. Em julho o saldo das transações correntes ficou negativo em US\$ $0,717 \mathrm{bi}$, atenuado pelo saldo positivo de agosto de US\$1,354bi, conforme dados preliminares do Bacen. No período jan-jul/2007 já entraram US $\$ 18,234 \mathrm{bi}$ em renda fixa contra uma saldo negativo de US\$4,955, no mesmo período do ano passado. Embora o saldo das transações corrente seja positivo no ano, permanece a tendência estrutural de queda, conforme mostra gráfico 1, abaixo.

Gráfico 1. Evolução do Saldo das Transações Correntes

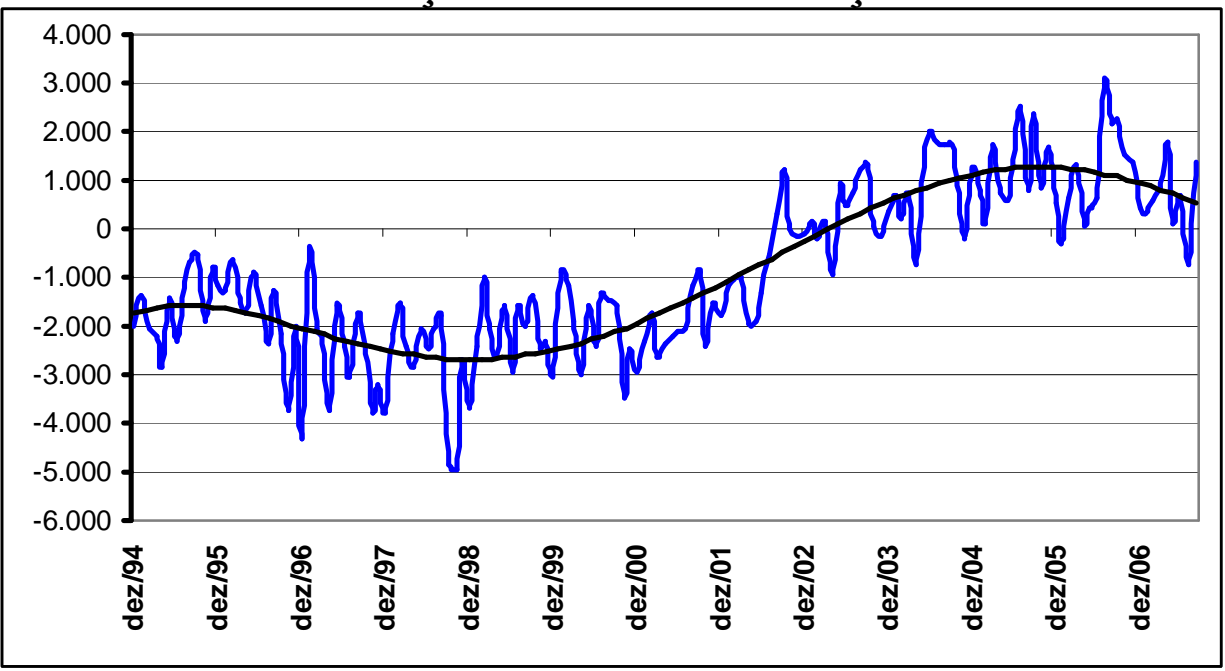

Muitos analistas têm repetidamente vangloriado o setor exportador brasileiro, por ser capaz de manter a performance exportadora. Dois fatos adicionais devem ser contrastados com este otimismo superficial. O primeiro é que o crescimento das exportações está baseado no preço e não no quantum. Os preços, até o momento, foram determinados por conjuntura internacional favorável. Se houver, como parece ser o caso, redução do ritmo de crescimento da economia mundial com uma queda nos preços de commodities, o desempenho em valor da

\footnotetext{
* Doutorando em Economia pela UFPR. Professor de Economia e Coordenador de Pós-Graduação em Finanças Corporativas e Mercados Financeiros na UniBrasil. Membro da equipe técnica do Boletim. Endereço eletrônico: joaobasilio@unibrasil.com.br.
} 
balança comercial será ameaçado. O segundo fato é o aumento não desprezível de US\$ 0,961bi no saldo negativo da balança de serviços e de rendas em jan-jul/2007. A trajetória atual para as transações correntes é de deterioração. Como proporção do PIB, o saldo em transações corrente caiu pela metade nos últimos 12 meses, indo de 1,28\% para míseros 0,60\% (tabela 1). O saldo em transações acumulado entre janeiro e julho caiu 37\% em 2007 em relação ao período anterior, uma queda significativa que não pode ser ignorada. $O$ principal motivo foi o aumento de $28 \%$ das importações e um pequeno aumento do déficit em rendas e serviços de $4,4 \%$.

Tabela 1. Balanço de Pagamentos

\begin{tabular}{|c|c|c|c|c|c|}
\hline \multirow{2}{*}{ Discriminação } & \multicolumn{3}{|c|}{$2006 *$} & \multicolumn{2}{|c|}{$2007 *$} \\
\hline & Jul & Jan-Jul & Ano & Jul & Jan-Jul \\
\hline Balança comercial (FOB) & 5659 & 25192 & 46458 & 3347 & 23985 \\
\hline Exportações & 13651 & 74708 & 137807 & 14120 & 87333 \\
\hline Importações & 7992 & 49516 & 91350 & 10773 & 63348 \\
\hline Serviços e rendas & -2940 & -21746 & -37143 & -4456 & -22707 \\
\hline Transferências unilaterais (líquido) & 336 & 2372 & 4306 & 392 & 2388 \\
\hline Transações correntes & 3055 & 5819 & 13621 & -717 & 3666 \\
\hline Conta capital e financeira & 845 & 6612 & 15982 & 7024 & 66836 \\
\hline Conta capital ${ }^{1 /}$ & 58 & 488 & 869 & 67 & 357 \\
\hline Conta financeira & 787 & 6124 & 15113 & 6957 & 66479 \\
\hline Investimento direto (líquido) & 930 & 3813 & -9420 & 3762 & 28088 \\
\hline Ações & 401 & 4155 & 6801 & 6451 & 13348 \\
\hline Títulos de Renda Fixa & -482 & -4955 & 2773 & 1120 & 18234 \\
\hline Derivativos & 12 & 231 & 383 & 60 & 208 \\
\hline Outros investimentos2/ & -74 & 2881 & 14577 & -4435 & 6599 \\
\hline Erros e omissões & 17 & -354 & 965 & 1345 & -1240 \\
\hline $\begin{array}{l}\text { Variação reservas ( - = aumento) } \\
\text { Memo: }\end{array}$ & - 3917 & - 12077 & -30569 & -7652 & -69263 \\
\hline Resultado global do balanço & 3917 & 12077 & 30569 & 7652 & 69263 \\
\hline Transações correntes/PIB (\%) & - & 0,96 & 1,28 & - & 0,60 \\
\hline IED/PIB $(\%)$ & - & 1,47 & 1,76 & - & 4,02 \\
\hline $\begin{array}{l}\text { 1/ Inclui transferências de patrimôni } \\
2 \text { / Registra créditos comerciais, emp } \\
\text { regularização. }\end{array}$ & stimos, & depó & itros at & pass & erações d \\
\hline
\end{tabular}

Por traz deste desempenho está, evidentemente, o câmbio. Mas o câmbio em si não é a causa fundamental. A causa fundamental é a política monetária que, através de elevada taxas de juros em nível, cria um enorme espaço de arbitragem ao quebrar a "paridade internacional da taxa de juros", permitindo e estimulando um enorme fluxo de capitais especulativos em direção ao Brasil.

A teoria macroeconômica para economias abertas com mobilidades de capitais estabelece que a taxa interna real de juros deva ser igual à taxa real de juros internacional mais 136 
um prêmio de risco para que o câmbio seja estável. O nível em que se encontra a taxa real de juros é, sabidamente, o mais alto do mundo e muito longe, portanto, de uma "condição de equilíbrio" com prêmio de risco embutido. Daí a apreciação exagerada do câmbio. A questão crucial do momento é que a redução lenta e gradativa dos juros nos últimos anos não foi suficiente para eliminar o enorme espaço de arbitragem existente entre a bondosa política monetária do BACEN e os interesses arbitradores. A teoria não tem funcionado em sua plenitude no Brasil.

Atente o leitor ao fato de que a existência de agentes arbitradores no mercado pode ser benéfica, na medida em que força as políticas monetárias garantirem a "condição de paridade da taxa de juros", a fim de que haja estabilidade no câmbio. A arbitragem equaliza as taxas de juros internacionais. O rompimento da paridade, no caso de manutenção da Selic em níveis internacionalmente elevados, irá aumentar a rentabilidade dos investimentos especulativos, adicionando mais retorno ao retorno existente, pois irá estimular uma valorização cambial, o que atrairá mais dólares e mais apreciação, num ciclo favorável ao arbitrador e prejudicial ao país. A política monetária está desprezando uma parte essencial da teoria macroeconômica ao relegar o problema da paridade da taxa de juros.

A discussão sobre câmbio deve, portanto, ser precedida de uma avaliação da política monetária, a grande responsável pela maior valorização da moeda em relação ao dólar do mundo. É fato que o dólar está se desvalorizando mundialmente. Mas em nenhum outro país a moeda nacional tem se valorizado tanto quanto no Brasil e a causa disso é, na maior parte, a política monetária de juros altos em nível. É interessante notar que o próprio EUA não faz nenhuma cerimônia em desvalorizar sua moeda como meio equilibrar seu balanço de pagamentos. O mesmo faz a China e asiáticos para exportarem mais. Apenas aqui nos trópicos competir via câmbio parece ser uma heresia econômica.

A política monetária é a principal responsável pela deterioração do saldo das transações correntes, que reflete o lado real da economia, e pelo aumento da vulnerabilidade intrínseca da conta financeira, por estimular a entrada massiva de capital especulativo. Há um aumento de vulnerabilidade intrínseca, pois mesmo que o saldo financeiro de US\$ 66.836 bi seja maior que um possível saldo negativo nas trocas correntes, dando garantias de cobertura, é um tipo de cobertura altamente volátil. Além do que a cobertura global baseada em fluxos financeiros é uma estratégia míope, pois desarticula o equilíbrio estrutural vindo do setor real (em transações correntes). Em síntese, a política monetária conduz a uma troca de equilíbrio externo baseado em transações correntes, destruindo capacidade interna de produção, em 
nome de um equilíbrio baseado em fluxos de capital especulativo, com aumento de vulnerabilidade intrínseca ao tipo de capital que entra no país.

Esta troca das condições de equilíbrio externo por ser constatada pelo crescimento expressivo da conta financeira em ações e renda fixa (tabela1). Boa parte do lastro de renda fixa são papéis do governo influenciados pela Selic. A taxa de juros elevada cria um enorme espaço de arbitragem por quebrar "condição de paridade da taxa de juros". Isto permite que os investidores nacionais e internacionais emprestem recursos baratos fora do país e apliquem em títulos públicos e privados brasileiros, que pagam juros desproporcionalmente maiores, aproveitando o diferencial de taxas. A atual política monetária amplia enormemente a oferta de dólares, que já é alta por conta de um aumento no investimento estrangeiro direto, o qual aumentou de US\$3,813 no período jan-jul/2006 para US\$28,088 bi em jan-jul/2007.

A estratégia da política econômica brasileira para o equilíbrio das contas externas, baseada em preços de commodities (que garante aumentos no montante das exportações) e entrada de capital especulativo, é arriscada e insustentável. A rentabilidade alta garantida pela taxa básica de juros, ao atrair capital especulativo, força uma valorização da moeda nacional, o que por sua vez aumenta ainda mais a rentabilidade dos investimentos especulativos, atraindo mais capital. O ciclo de valorização cambial é acionado novamente, de forma que há um ganho excedente no circuito financeiro com correlata perda de dinamismo no setor real. Os arbitradores montam posições futuras compradas, apostando em mais valorização, de forma que os mercados derivativos amplificam o problema. Os fluxos de investimentos especulativos (arbitradores de taxas de juros) devem ser desestimulados, e para isso é necessário garantir a "paridade das taxas de juros" através da redução da Selic, cujo nível é muito alto para o padrão internacional. Observe-se que não estamos defendendo, em nenhum momento, a eliminação dos fluxos arbitradores, pois sua existência é um importante para manutenção de liquidez que serve de base para os agentes que precisam fazer hedge por questões operacionais. A diferença entre remédio e o veneno é a dose.

Mais do que qualquer outro determinante, o câmbio hoje é reflexo da política de juros. Esta em discussão, no país, várias propostas de políticas econômicas que poderiam reverter a tendência de valorização cambial como, por exemplo, estimular o investimento brasileiro no exterior como fonte de demanda de câmbio. Ajuda, mas não resolve. Estas estratégias têm seu valor e ajudam, mas não serão suficientes para anular o efeito da quebra da paridade internacional dos juros. O equilíbrio internacional entre juros internos e externos é urgente e necessário, pois a aproximação da classificação do país com "investment grade", por 
vir em breve, tende a deteriorar ainda mais o valorizado câmbio brasileiro. É preciso recuperar o terreno do diferencial dos juros enquanto há tempo, mas essa não parece ser a preocupação principal das autoridades monetárias, atualmente concentrada em controle de preços.

Não temos inflação de demanda no país, o choque de preços agrícola já passou e o problema do aquecimento da demanda é causado por crédito no consumo. Este pode ser desestimulado por medidas que afetam o equilíbrio microeconômico de oferta e demanda de crédito no segmento de credito à PF e PJ de curto prazo, como, por exemplo, aumentar o custo de captação via IOF ou compulsórios específicos. Isto altera a estrutura dos ativos (aplicações) e passivos (captações) do sistema financeiro. Ou seja, há espaço para convergir a taxa de nominal interna de juros para 8 ou $9 \%$ aa nos próximos meses sem perda de controle inflacionário. Na próxima reunião, a fim de não aumentar o fosso da paridade internacional taxa de juros, o Copom precisa acompanhar o FED, reduzindo a selic em 0,5 pontos percentuais.

Em permanecendo a atual visão restrita a preços da política monetária, em que a única variável de controle é a taxa básica de juros (o remédio universal para todos os males inflacionários), o setor industrial e os trabalhadores deverão se preparar para câmbios mais valorizados e seus efeitos deletérios. A melhor maneira de atenuar a pressão cambial é fazer com que a política monetária dos próximos meses se volte à eliminação do espaço de arbitragem das taxas de juros. 


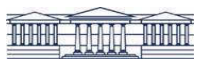

UFPR 